\title{
Albuterol Delivery by 4 Different Nebulizers Placed in 4 Different Positions in a Pediatric Ventilator In Vitro Model
}

\author{
Ariel Berlinski MD and J Randy Willis RRT-NPS
}

\begin{abstract}
BACKGROUND: The type of aerosol generator and the position in the ventilator circuit are crucial to determine aerosol delivery during mechanical ventilation. We compared lung deposition of albuterol aerosols generated by $\mathbf{4}$ different nebulizers placed in-line in $\mathbf{4}$ different positions in a pediatric ventilator model. METHODS: Two brands of continuously operated jet nebulizer $(6 \mathrm{~L} /$ min, oxygen), an ultrasonic, and a vibrating mesh were compared when placed at the ventilator, the humidifier, the Y-piece, and $30 \mathrm{~cm}$ before the Y-piece. The jet, ultrasonic, and vibrating mesh nebulizers were operated for 5,15 , and $15 \mathrm{~min}$, respectively. The tested solutions contained $2.5 \mathrm{mg}$, $5.0 \mathrm{mg}$, and $7.5 \mathrm{mg}$ of albuterol sulfate. The ventilator settings were: pressure-regulated volume control mode, tidal volume $200 \mathrm{~mL}$, breathing frequency 20 breaths $/ \mathrm{min}, \operatorname{PEEP} 5 \mathrm{~cm} \mathrm{H_{2 }} \mathrm{O}_{,} \mathrm{F}_{\mathrm{IO}_{2}} 0.4$, inspiratory time $0.75 \mathrm{~s}$, bias flow $2 \mathrm{~L} / \mathrm{min}$, and heater $37^{\circ} \mathrm{C}$. The circuit was connected in series to a $5.5 \mathrm{~mm}$ cuffed endotracheal tube, a deposition filter, and a lung model. Albuterol was measured by spectrophotometry. RESULTS: Intra-device comparison: the jet and vibrating mesh nebulizers performed best at either the ventilator or humidifier, and worst at the Y-piece. The ultrasonic nebulizer performed best at the humidifier and worst at the Y-piece. Inter-device comparison: the vibrating mesh nebulizer outperformed both jet nebulizers at all tested positions, and the ultrasonic nebulizer when placed at either the ventilator or the humidifier. Lung deposition increased for the jet and ultrasonic nebulizers, but not for vibrating mesh nebulizer, when increasing the loading volume while maintaining the nominal dose. CONCLUSIONS: The vibrating mesh nebulizer was the most efficient device. The nebulizers were more efficient when placed at either the ventilator or the humidifier, and less efficient when placed at either the $Y$-piece or $30 \mathrm{~cm}$ from the Y-piece. These conclusions are valid for the tested conditions. Data regarding optimization of operating conditions should not be extrapolated among nebulizers of different operating principles. Key words: mechanical ventilation; albuterol; jet nebulizer; vibrating mesh nebulizer; ultrasonic nebulizer; position; pediatrics; aerosol; humidifier. [Respir Care 2013;58(7):1124-1133. () 2013 Daedalus Enterprises]
\end{abstract}

\section{Introduction}

Pediatric patients receiving mechanical ventilation are often prescribed nebulized therapy. The ideal device and

The authors are affiliated with Arkansas Children's Hospital, Little Rock, Arkansas. Dr Berlinski is also affiliated with the Pulmonology Section, Department of Pediatrics, University of Arkansas for Medical Sciences, and with the Pediatric Aerosol Research Laboratory, Arkansas Children's Hospital Research Institute, Little Rock, Arkansas

Mr Willis presented a version of this paper at the 56th AARC Congress, held December 6-9, 2010, in Las Vegas, Nevada.

Dr Berlinski has disclosed relationships with Johnson \& Johnson, MPEX Pharmaceutical, Gilead Sciences, Philips, and S\&T Technologies. Mr Wil- operating conditions are yet to be established. Although direct quantification of lung deposition would be the most accurate method to determine best device/operating conditions, ethical considerations regarding blood draws and

\footnotetext{
lis has disclosed no conflicts of interest. The Pediatric Aerosol Research Laboratory at Arkansas Children's Hospital Research Institute was partially established by, and receives partial support from, the George Endowment for Asthma.

Correspondence: Ariel Berlinski MD, Pulmonary Medicine Division, Department of Pediatrics, University of Arkansas for Medical Sciences, 1 Children's Way, Slot 512-17, Little Rock AR 72202. E-mail: BerlinskiAriel@uams.edu.
}

DOI: $10.4187 /$ respcare.02074 


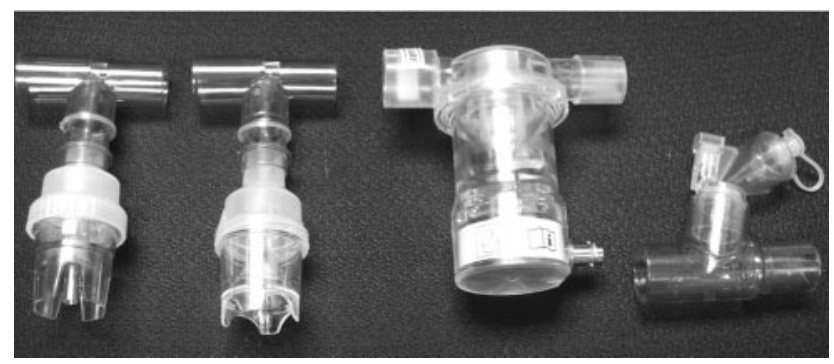

Fig. 1. Nebulizers tested. From right to left: Aerogen Solo, Maquet Ultrasonic model N06302595E400E, Salter 8900, and Hudson Updraft II Opti-Neb.

use of radio-labeled studies have limited their use. ${ }^{1}$ Investigators have resorted to in vitro models, for which good in vivo/in vitro correlation has been established.2,3

SeE the Related Editorial on Page 1255

Delivery efficiency depends on many factors such as type of aerosol generator, position, endotracheal tube (ETT) size, and others. ${ }^{4,5}$ The type of aerosol generator can determine a several-fold difference in drug delivery. ${ }^{6}$ Currently jet nebulizers, ultrasonic nebulizers, and vibrating mesh nebulizers are available for use with ventilator circuits. Several authors have shown that the position of the aerosol generator can greatly influence drug delivery to the patient. ${ }^{7-12}$ However, most of these studies were done using adult type settings and therefore are not applicable to pediatric scenarios..$^{7-11}$

In this study we compared drug delivery efficiency and absolute lung deposition of 2 jet nebulizers, an ultrasonic nebulizer, and a vibrating mesh nebulizer, placed in 4 different positions in a pediatric ventilator circuit model, using different albuterol doses and concentrations.

\section{Methods}

This study was performed at the Pediatric Aerosol Research Laboratory, Arkansas Children's Hospital Research Institute, and Arkansas's Children's Hospital, Little Rock, Arkansas.

\section{Nebulizers}

Four different brands of nebulizer, representing 3 different operating principles were tested (Fig. 1). Two continuously operated jet nebulizers were tested: Salter 8900 (Salter Labs, Arvin, California) and Hudson Updraft II Opti-Neb (Teleflex Medical, Research Triangle Park, North Carolina). Both nebulizers were connected to the circuit with a spring-loaded T-piece (Airlife Valved Tee adapter, Thayer Medical, Tucson, Arizona) and operated with

\section{QUICK LOOK}

\section{Current knowledge}

Aerosol lung deposition during pediatric mechanical ventilation is affected by the type of aerosol generator and its position in the circuit, endotracheal tube size, humidification, and ventilation mode. The optimal combination of each nebulizer type and position is unknown.

\section{What this paper contributes to our knowledge}

In an in-vitro pediatric ventilator model, a vibratingmesh nebulizer outperformed jet and ultrasonic nebulizers, irrespective of position in the ventilator circuit. Aerosol deposition was maximized with the nebulizer at the ventilator outlet or immediately after the humidifier. Deposition was less with the nebulizer at the Ypiece or $30 \mathrm{~cm}$ from the Y-piece.

central oxygen at $6 \mathrm{~L} / \mathrm{min}$ for $5 \mathrm{~min}$. The ventilator settings were adjusted during nebulization to compensate for the increase in flow. One ultrasonic nebulizer, model N06302595E400E, Maquet, Solna, Sweden, and one vibrating mesh nebulizer, Solo, Aerogen, Galway, Ireland, were also tested. Both devices were connected to the ventilator circuit with a T-piece and were operated for $15 \mathrm{~min}$. No ventilator adjustments were required to operate these 2 devices. The length of operation was decided after preliminary testing showed that these intervals allowed nebulization to dryness for all devices. Table 1 compares the different characteristics of the nebulizers, including the cost of delivering different amounts of albuterol sulfate for 3 different lengths of time.

\section{Solutions}

Several loading doses, volumes, and concentrations of albuterol sulfate nebulizer solution were tested. Initially, $2.5 \mathrm{mg} / 3 \mathrm{~mL}, 5.0 \mathrm{mg} / 3.5 \mathrm{~mL}$, and $7.5 \mathrm{mg} / 4 \mathrm{~mL}$ were used. These solutions were made of single bullet units of albuterol sulfate $2.5 \mathrm{mg} / 3 \mathrm{~mL}$ (Nephron Pharmaceuticals, Orlando, Florida) and $0.5 \mathrm{mg} / \mathrm{mL}$ (Nephron Pharmaceuticals, Orlando, Florida). Previous research demonstrated that higher loading volumes determine higher drug output. ${ }^{13}$ Therefore, we also tested 2 other solutions with the same nominal dose $(2.5 \mathrm{mg})$ and different loading volumes ( $3.5 \mathrm{~mL}$ and $4 \mathrm{~mL}$ ) to evaluate the effect of increasing the loading volume on lung dose.

\section{Positions of Aerosol Generators}

All nebulizers were tested in 4 different positions (Fig. 2). Position A was at the ventilator on the inspiratory side. 
Table 1. Features of Tested Nebulizers

\begin{tabular}{|c|c|c|c|c|}
\hline & $\begin{array}{l}\text { Hudson Updraft II } \\
\text { Opti-Neb }\end{array}$ & $\begin{array}{r}\text { Salter } \\
8900\end{array}$ & $\begin{array}{l}\text { Maquet } \\
\text { Ultrasonic }\end{array}$ & $\begin{array}{l}\text { Aerogen Solo } \\
\text { Vibrating Mesh }\end{array}$ \\
\hline Weight, g & 16 & 16 & 125 & 14 \\
\hline Dead volume & +++ & +++ & ++ & + \\
\hline External gas source required & Yes & Yes & No & No \\
\hline $\begin{array}{l}\text { Provides additional flow to the circuit requiring adjustment } \\
\text { of ventilator settings }\end{array}$ & Yes & Yes & No & No \\
\hline Effect on medication temperature & $\downarrow$ & $\downarrow$ & $\uparrow$ & $=$ \\
\hline \multicolumn{5}{|l|}{ Cost for 1 treatment* } \\
\hline $2.5 \mathrm{mg} / 3 \mathrm{~mL}$ & 3.30 & 3.61 & 2.35 & 43.98 \\
\hline $5.0 \mathrm{mg} / 3.5 \mathrm{~mL}$ & 3.64 & 3.95 & 2.69 & 44.32 \\
\hline $7.5 \mathrm{mg} / 4 \mathrm{~mL}$ & 3.98 & 4.29 & 3.03 & 44.66 \\
\hline \multicolumn{5}{|l|}{ Cost for 28 treatments* } \\
\hline $2.5 \mathrm{mg} / 3 \mathrm{~mL}$ & 1.08 & 1.12 & 1.18 & 2.53 \\
\hline $5.0 \mathrm{mg} / 3.5 \mathrm{~mL}$ & 1.42 & 1.46 & 1.52 & 2.87 \\
\hline $7.5 \mathrm{mg} / 4 \mathrm{~mL}$ & 1.76 & 1.80 & 1.86 & 3.21 \\
\hline \multicolumn{5}{|l|}{ Cost for 120 treatments* } \\
\hline $2.5 \mathrm{mg} / 3 \mathrm{~mL}$ & 1.02 & 1.06 & 1.15 & 1.35 \\
\hline $5.0 \mathrm{mg} / 3.5 \mathrm{~mL}$ & 1.36 & 1.40 & 1.49 & 1.69 \\
\hline $7.5 \mathrm{mg} / 4 \mathrm{~mL}$ & 1.70 & 1.74 & 1.83 & 2.03 \\
\hline
\end{tabular}

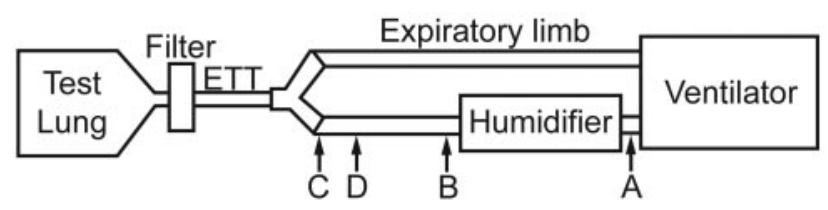

Fig. 2. Testing set-up. Position A: At the ventilator on the inspiratory side. Position B: Between the humidifier and the inspiratory limb. Position C: Between the inspiratory limb and the Y-piece. Position D: In the inspiratory limb, $30 \mathrm{~cm}$ before the $Y$-piece. $E T T=$ endotracheal tube.

Position B was between the humidifier and the inspiratory limb of the ventilator circuit. Position $\mathrm{C}$ was between the inspiratory limb of the ventilator circuit and the Y-piece. Position D was in the inspiratory limb of the ventilator circuit, at $30 \mathrm{~cm}$ before the Y-piece. The latter was achieved by cutting the circuit at $30 \mathrm{~cm}$ from the Y-piece, re-threading the heated wire, and placing a T-piece between the 2 pieces of circuit.

\section{Pediatric Ventilator Model}

A previously described pediatric ventilator model was used. ${ }^{6}$ Briefly, a ventilator (Servo-i, Maquet, Solna, Sweden) operated in pressure-regulated volume control mode connected to a $1.83 \mathrm{~m}$ long and $22 \mathrm{~mm}$ inner diameter heated wire ventilator circuit (Evaqua, Fisher \& Paykel,
Auckland, New Zealand) was used. The settings were: tidal volume $\left(\mathrm{V}_{\mathrm{T}}\right) 200 \mathrm{~mL}$, breathing frequency 20 breaths/ min, PEEP $5 \mathrm{~cm} \mathrm{H}_{2} \mathrm{O}, \mathrm{F}_{\mathrm{IO}_{2}} 0.4$, inspiratory time $0.75 \mathrm{~s}$, inspiratory rise $0.15 \mathrm{~s}$, flow trigger 3 , bias flow $2 \mathrm{~L} / \mathrm{min}$, and heater $37 \pm 1.5^{\circ} \mathrm{C}$. The circuit was connected to a $5.5 \mathrm{~mm}$ inner diameter cuffed ETT (Mallinckrodt Lo-Pro, Tyco/Mallinckrodt-Nellcor, Pleasanton, California). A lung model (SmartLung $600 \mathrm{~mL}$, IMT Medical, Buchs, Switzerland) was connected in series, and a low-dead-space filter folder was interposed between them. The cuff was inflated to provide a closed circuit.

\section{Testing Procedure}

A new respiratory filter (Pari Respiratory Equipment, Midlothian, Virginia) was placed in the filter holder before each run. The filter holder was sealed with Teflon tape, and the efficiency of the seal was verified by checking the returned $\mathrm{V}_{\mathrm{T}}$. The filter was removed upon completion of the run time, eluted with ultrapure water, and the washings were tested for albuterol with a spectrophotometer (BioMate 3 UV-Vis Spectrophotometer, Thermo Fisher Scientific, Waltham, Massachusetts) at $276 \mathrm{~nm} \cdot{ }^{14}$ The amount of drug captured in the filter was considered the lung dose. Five units of each aerosol generator were tested in each of the 4 positions, with $2.5 \mathrm{mg} / 3 \mathrm{~mL}, 5.0 \mathrm{mg} / 3.5 \mathrm{~mL}$ and $7.5 \mathrm{mg} / 4 \mathrm{~mL}$. All positions except position D were tested with solutions of $2.5 \mathrm{mg} / 3.5 \mathrm{~mL}$ and $2.5 \mathrm{mg} / 4 \mathrm{~mL}$. 


\section{Statistical Analysis}

Data were compared as lung dose ( $\mu \mathrm{g}$ of albuterol) and drug delivery efficiency $(\%)$. The latter was calculated as:

\author{
Efficiency $=[$ drug captured in the filter $(\mu \mathrm{g}) /$ \\ drug placed in the nebulizer $(\mu \mathrm{g})] \times 100$
}

Intra-device and inter-device comparisons were performed at all tested positions with each tested solution, using analysis of variance for repeated measures and analysis of variance, respectively, followed by the Tukey test when multiple comparison analysis was required. Differences within each device placed at each tested position between solutions of the same volume and different concentrations $(2.5 \mathrm{mg} / 3.5 \mathrm{mg}$ vs $5.0 \mathrm{mg} / 3.5 \mathrm{~mL}, 2.5 \mathrm{mg} /$ $4 \mathrm{~mL}$ vs $7.5 \mathrm{mg} / 4 \mathrm{~mL}$, and $2.5 \mathrm{mg} / 3 \mathrm{~mL}$ vs $2.5 \mathrm{mg} / 4 \mathrm{~mL}$ ) were tested using a 2-tailed paired $t$ test. A statistical software package (MDAS 2.0, Eskay Software, Silver Spring, Maryland) was used to analyze the data. A $P$ value $<.05$ was considered statistically significant.

\section{Results}

\section{Intra-device Comparison}

The vibrating mesh nebulizer performed best and worst when placed at either the humidifier or ventilator and $\mathrm{Y}$ piece, respectively, for all tested solutions $(P<.01)$ (Fig. 3). These results were true for lung dose and delivery efficiency (Table 2). The difference in lung dose ranged from 3.2-fold with the $7.5 \mathrm{mg} / 4 \mathrm{~mL}$ solution to 4.3 -fold with the $2.5 \mathrm{mg} / 3.5 \mathrm{~mL}$ solution.

The Hudson nebulizer performed best and worse when placed at either the humidifier or ventilator and Y-piece, respectively, for all tested solutions $(P<.01)$ (see Fig. 3). These results were true for lung dose and delivery efficiency (see Table 2). The difference in lung dose ranged from 2.1 -fold with the $7.5 \mathrm{mg} / 4 \mathrm{~mL}$ solution to 4 -fold with the $2.5 \mathrm{mg} / 4 \mathrm{~mL}$ solution.

The ultrasonic nebulizer performed best and worse when placed at the humidifier and Y-piece, respectively, for all tested solutions $(P<.01)$ (see Fig. 3). These results were true for lung dose and delivery efficiency (see Table 2). The difference in lung dose ranged from 2-fold with the $2.5 \mathrm{mg} / 3 \mathrm{~mL}$ solution to 5.7 -fold with the $7.5 \mathrm{mg} / 4 \mathrm{~mL}$ solution.

The Salter nebulizer performed best and worse when placed at either the humidifier or ventilator and Y-piece, respectively, for all tested solutions $(P<.01)$ (see Fig. 3). These results were true for lung dose and delivery efficiency (see Table 2). The difference in lung dose ranged from 1.6-fold with the $2.5 \mathrm{mg} / 3 \mathrm{~mL}$ solution to 2.9 -fold with the $7.5 \mathrm{mg} / 4 \mathrm{~mL}$ solution.

\section{Inter-device Comparison}

When placed at the ventilator, the vibrating mesh nebulizer outperformed all other delivery devices, irrespective of solution tested $(P<.001)$ (Fig. 4). These results were true for lung dose and delivery efficiency (see Table 2). The ultrasonic nebulizer achieved higher lung dose than the jet nebulizers for some of the solutions tested. Lung dose differences among devices ranged from 5.7 -fold with the $2.5 \mathrm{mg} / 3.5 \mathrm{~mL}$ solution to 9.3 -fold with the $2.5 \mathrm{mg} /$ $3 \mathrm{~mL}$ solution.

When placed at the humidifier, the vibrating mesh nebulizer outperformed all other delivery devices with all solutions tested, except for the ultrasonic nebulizer using the $7.5 \mathrm{mg} / 4 \mathrm{~mL}$ solution $(P<.001)$ (see Fig. 4). These results were true for lung dose and delivery efficiency (see Table 2). The ultrasonic nebulizer was also superior to both jet nebulizers $(P<.01)$. Lung dose differences among devices ranged from 7.1-fold with the $2.5 \mathrm{mg} / 4 \mathrm{~mL}$ solution to 8.2 -fold with the $5.0 \mathrm{mg} / 3.5 \mathrm{~mL}$ solution.

When placed at the Y-piece, the vibrating mesh nebulizer outperformed both jet nebulizers for all solutions tested $(P<.001)$ (see Fig. 4). The vibrating mesh nebulizer was only superior to the ultrasonic nebulizer when using the $7.5 \mathrm{mg} / 4 \mathrm{~mL}$ solution $(P<.01)$. These results were true for lung dose and delivery efficiency (see Table 2). Differences in lung dose among devices ranged from 3.7-fold with the $5.0 \mathrm{mg} / 4 \mathrm{~mL}$ solution to 11.2 -fold with the $7.5 \mathrm{mg} /$ $4 \mathrm{~mL}$ solution.

When placed $30 \mathrm{~cm}$ before the Y-piece, the vibrating mesh nebulizer outperformed both jet nebulizers, irrespective of solution tested $(P<.001)$ (see Fig. 4). The vibrating mesh nebulizer also performed better than the ultrasonic nebulizer with the $7.5 \mathrm{mg} / 4 \mathrm{~mL}$ solution. These results were true for lung dose and delivery efficiency (see Table 2). The ultrasonic nebulizer was also superior to both jet nebulizers $(P<.01)$. Lung dose differences among devices ranged from 3.5 -fold with the $2.5 \mathrm{mg} / 3 \mathrm{~mL}$ solution to 5.4 -fold with the $7.5 \mathrm{mg} / 4 \mathrm{~mL}$ solution.

\section{Evaluation of Changes in Loading Volume/Nominal Dose Effect on Lung Dose}

When albuterol solutions of $2.5 \mathrm{mg} / 3.5 \mathrm{~mL}$ and $5.0 \mathrm{mg} /$ $3.5 \mathrm{~mL}$ were compared, lung dose was higher with the latter in all positions and nebulizers tested $(P<.001)$, except for the ultrasonic nebulizer at the ventilator $(P=.29)$ (Table 3). 


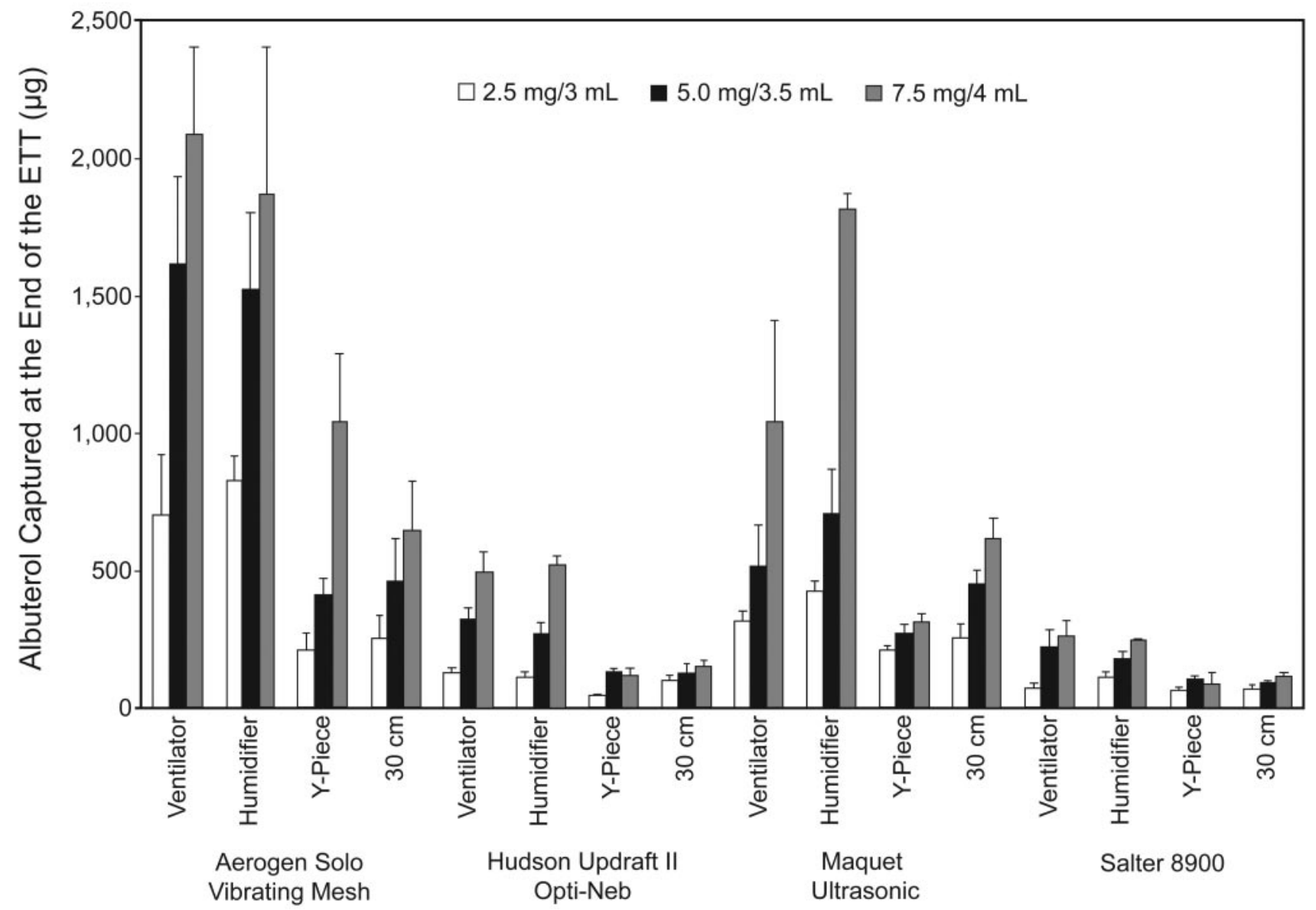

Fig. 3. Intra-device comparison of albuterol captured at the end of the endotracheal tube (lung dose). With the Updraft II Opti-Neb jet nebulizer, lung dose with the $2.5 \mathrm{mg} / 3 \mathrm{~mL}$ solution when placed at the Y-piece was lower than all, and lung dose with the $5.0 \mathrm{mg} / 3.5 \mathrm{~mL}$ and $7.5 \mathrm{mg} / 4 \mathrm{~mL}$ solutions when positioned at the ventilator was similar to humidifier and was greater than at the $\mathrm{Y}$-piece and $30 \mathrm{~cm}$ from the Y-piece. With the Salter 8900 jet nebulizer, lung dose with the $2.5 \mathrm{mg} / 3 \mathrm{~mL}$ solution when placed at the humidifier was greater than all other positions, and lung dose with the $5.0 \mathrm{mg} / 3.5 \mathrm{~mL}$ and $7.5 \mathrm{mg} / 4 \mathrm{~mL}$ solutions when positioned at the ventilator was similar to humidifier and was greater than Y-piece and $30 \mathrm{~cm}$ from the $\mathrm{Y}$-piece. With the Maquet ultrasonic nebulizer, lung dose with the $2.5 \mathrm{mg} / 3 \mathrm{~mL}$ solution when placed at the humidifier was greater than all other positions, and also lung dose was greater at the ventilator than at the $Y$-piece; output with the $5.0 \mathrm{mg} / 3.5 \mathrm{~mL}$ solution when placed at the humidifier was greater than the $Y$-piece and $30 \mathrm{~cm}$ from the $Y$-piece and lung dose was greater at the ventilator than at the $Y$-piece; lung dose with the $7.5 \mathrm{mg} / 4 \mathrm{~mL}$ solution when placed at the humidifier was greater than all other positions, and lung dose was greater at the ventilator than at the Y-piece and $30 \mathrm{~cm}$ from the Y-piece. With the Aerogen Solo vibrating mesh nebulizer, lung dose with all solutions tested when positioned at the ventilator was similar to humidifier and was greater than Y-piece and $30 \mathrm{~cm}$ from the Y-piece.

When albuterol solutions of $2.5 \mathrm{mg} / 4 \mathrm{~mL}$ and $7.5 \mathrm{mg} /$ $4 \mathrm{~mL}$ were compared, lung dose was higher with the latter in all positions and nebulizers tested $(P<.001)$, except for the Salter nebulizer at the Y-piece $(P=.09)$ (see Table 3).

When albuterol solutions of $2.5 \mathrm{mg} / 3 \mathrm{~mL}$ and $2.5 \mathrm{mg} /$ $4 \mathrm{~mL}$ were compared, lung dose was higher with the latter except for the Hudson nebulizer at the Y-piece $(P=.08)$, the Salter nebulizer at the humidifier $(P=.39)$, the ultrasonic nebulizer at the ventilator $(P=.21)$ and the Y-piece $(P=.17)$. No differences were noted for the vibrating mesh nebulizer $(P=.54, P=.41$, and $P=.64$, when placed at the ventilator, humidifier, or Y-piece, respectively) (see Table 3).

\section{Discussion}

Mechanically ventilated pediatric patients are often prescribed nebulized albuterol. Delivery device and position in the ventilator circuit play an important role in determining how much albuterol reaches the end of the ETT. We compared 4 different devices placed in 4 different 
Table 2. Delivery Efficiency*

\begin{tabular}{|c|c|c|c|c|c|}
\hline \multirow{2}{*}{$\begin{array}{l}\text { Albuterol Nominal Dose/ } \\
\text { Loading Volume }\end{array}$} & \multirow{2}{*}{ Nebulizer } & \multicolumn{4}{|c|}{ Nebulizer Position } \\
\hline & & $\begin{array}{c}\text { At } \\
\text { Ventilator }\end{array}$ & $\begin{array}{c}\text { At } \\
\text { Humidifier }\end{array}$ & $\begin{array}{c}\text { At } \\
\text { Y-Piece }\end{array}$ & $\begin{array}{c}30 \mathrm{~cm} \text { Before } \\
\text { Y-piece }\end{array}$ \\
\hline \multirow[t]{4}{*}{$2.5 \mathrm{mg} / 3 \mathrm{~mL}$} & Hudson Updraft II Opti-Neb & $5.4 \pm 0.6$ & $4.7 \pm 0.8$ & $2.0 \pm 0.1$ & $4.3 \pm 0.8$ \\
\hline & Salter 8900 & $3.1 \pm 0.9$ & $4.6 \pm 0.9$ & $2.8 \pm 0.4$ & $2.9 \pm 0.7$ \\
\hline & Maquet Ultrasonic & $12.8 \pm 1.5$ & $17.1 \pm 1.5$ & $8.7 \pm 0.7$ & $10.5 \pm 2$ \\
\hline & Aerogen Solo vibrating mesh & $28.5 \pm 8.6$ & $33.3 \pm 3.6$ & $8.7 \pm 2.5$ & $10.3 \pm 3.3$ \\
\hline \multirow[t]{4}{*}{$5.0 \mathrm{mg} / 3.5 \mathrm{~mL}$} & Hudson Updraft II Opti-Neb & $6.6 \pm 0.8$ & $5.4 \pm 1$ & $2.8 \pm 0.3$ & $2.6 \pm 0.7$ \\
\hline & Salter 8900 & $4.5 \pm 1.3$ & $3.7 \pm 0.5$ & $2.2 \pm 0.2$ & $2.0 \pm 0.1$ \\
\hline & Maquet Ultrasonic & $10.4 \pm 3$ & $14.2 \pm 3.3$ & $5.6 \pm 0.6$ & $9.1 \pm 0.1$ \\
\hline & Aerogen Solo vibrating mesh & $32.4 \pm 6.4$ & $30.6 \pm 5.6$ & $8.3 \pm 1.2$ & $9.3 \pm 3.1$ \\
\hline \multirow[t]{4}{*}{$7.5 \mathrm{mg} / 4 \mathrm{~mL}$} & Hudson Updraft II Opti-Neb & $6.6 \pm 1$ & $7.0 \pm 0.4$ & $1.7 \pm 0.3$ & $2.1 \pm 0.3$ \\
\hline & Salter 8900 & $3.6 \pm 0.7$ & $3.4 \pm 0.5$ & $1.2 \pm 0.5$ & $1.6 \pm 0.1$ \\
\hline & Maquet Ultrasonic & $14.0 \pm 4.6$ & $24.3 \pm 0.8$ & $4.2 \pm 0.4$ & $8.3 \pm 1$ \\
\hline & Aerogen Solo vibrating mesh & $27.9 \pm 4.2$ & $25.0 \pm 7.1$ & $13.9 \pm 3.3$ & $8.7 \pm 2.4$ \\
\hline
\end{tabular}

* Values are mean $\pm \mathrm{SD}$ of 5 measurements, expressed as percentage and calculated as [drug captured in the filter $(\mu \mathrm{g}) / \mathrm{drug}$ placed in the nebulizer $(\mu \mathrm{g})] \times 100$

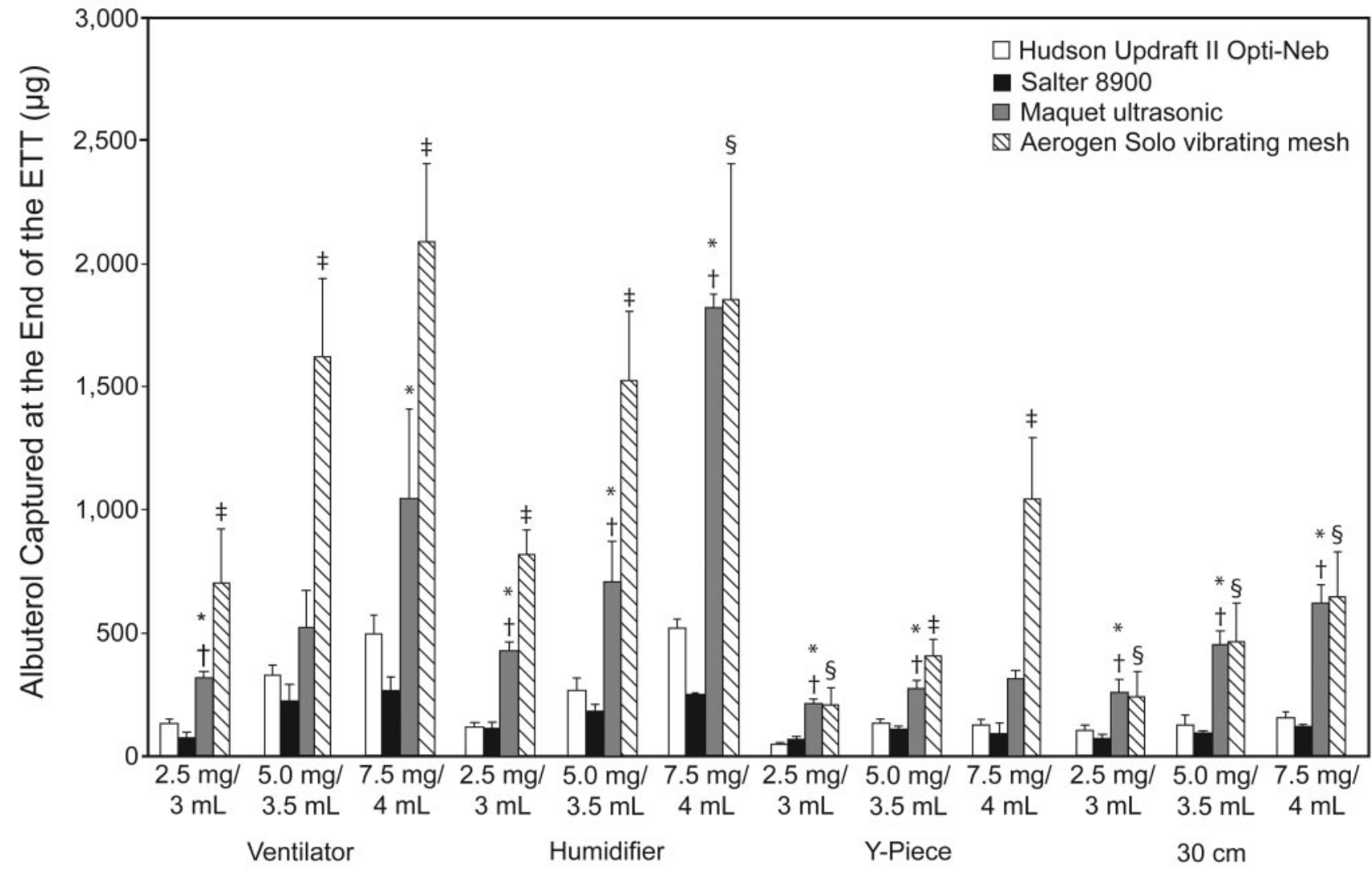

Fig. 4. Inter-device comparison. * Deposition with the Aerogen Solo vibrating mesh nebulizer was greater than with all other nebulizers $(P<.01)$. † Deposition with the Maquet ultrasonic nebulizer was greater than with the Salter 8900 nebulizer $(P<.05)$. $\neq$ Deposition with the Maquet ultrasonic nebulizer was greater than with the Hudson Updraft II Opti-Neb nebulizer $(P<.05)$. § Deposition with the Aerogen Solo vibrating mesh nebulizer was greater than with the Hudson Updraft II Opti-Neb and Salter 8900 nebulizers $(P<.01)$.

positions of the pediatric ventilator circuit model. The vibrating mesh device delivered the most albuterol to the end of the ETT. The Y-piece and either ventilator or humidifier were the worst and best positions to place the 
Table 3. Evaluation of the Effect of Changes in Nominal Dose and Loading Volume on Lung Dose

\begin{tabular}{|c|c|c|c|c|}
\hline \multirow{2}{*}{ Nebulizer } & \multirow{2}{*}{$\begin{array}{l}\text { Albuterol Nominal } \\
\text { Dose/Loading Volume }\end{array}$} & \multicolumn{3}{|c|}{ Nebulizer Position* } \\
\hline & & $\begin{array}{c}\text { At } \\
\text { Ventilator }\end{array}$ & $\begin{array}{c}\text { At } \\
\text { Humidifier }\end{array}$ & $\begin{array}{c}\text { At } \\
\text { Y-Piece }\end{array}$ \\
\hline \multirow[t]{5}{*}{ Hudson Updraft II Opti-Neb } & $2.5 \mathrm{mg} / 3 \mathrm{~mL}$ & $135.4 \pm 15.8$ & $117.5 \pm 19.4$ & $51 \pm 2.9$ \\
\hline & $2.5 \mathrm{mg} / 4 \mathrm{~mL}$ & $191.8 \pm 34.1 \dagger$ & $135.5 \pm 7.4 \dagger$ & $63.3 \pm 13.6$ \\
\hline & $7.5 \mathrm{mg} / 4 \mathrm{~mL} \ddagger$ & $497.6 \pm 76.7$ & $527.8 \pm 30.9$ & $129.3 \pm 22.2$ \\
\hline & $2.5 \mathrm{mg} / 3.5 \mathrm{~mL}$ & $246.8 \pm 29.7$ & $154.7 \pm 19.7$ & $66.8 \pm 13.2$ \\
\hline & $5.0 \mathrm{mg} / 3.5 \mathrm{~mL} \S$ & $330.6 \pm 39.3$ & $270.2 \pm 47.8$ & $137.5 \pm 13.6$ \\
\hline \multirow[t]{5}{*}{ Salter 8900} & $2.5 \mathrm{mg} / 3 \mathrm{~mL}$ & $76.4 \pm 21.5$ & $115.6 \pm 21.3$ & $70.9 \pm 9.6$ \\
\hline & $2.5 \mathrm{mg} / 4 \mathrm{~mL}$ & $127.9 \pm 19.6 \dagger$ & $103.9 \pm 21.2$ & $49.6 \pm 7.8$ \\
\hline & $7.5 \mathrm{mg} / 4 \mathrm{~mL}$ & $270.2 \pm 54.5 \|$ & $253.7 \pm 35.7 \|$ & $93.6 \pm 40.8$ \\
\hline & $2.5 \mathrm{mg} / 3.5 \mathrm{~mL}$ & $145.8 \pm 52.8$ & $117.6 \pm 28.1$ & $50.3 \pm 9$ \\
\hline & $5.0 \mathrm{mg} / 3.5 \mathrm{~mL} \S$ & $226.9 \pm 64.1$ & $185.6 \pm 25.4$ & $111.4 \pm 10.7$ \\
\hline \multirow[t]{5}{*}{ Maquet Ultrasonic } & $2.5 \mathrm{mg} / 3 \mathrm{~mL}$ & $319.5 \pm 38$ & $428.7 \pm 36.7$ & $216.4 \pm 16.3$ \\
\hline & $2.5 \mathrm{mg} / 4 \mathrm{~mL}$ & $431.1 \pm 136.6$ & $515.3 \pm 49.3 \dagger$ & $144.2 \pm 30.1$ \\
\hline & $7.5 \mathrm{mg} / 4 \mathrm{~mL} \ddagger$ & $1,048.9 \pm 346.4$ & $1,820 \pm 56.6$ & $316.9 \pm 30.9$ \\
\hline & $2.5 \mathrm{mg} / 3.5 \mathrm{~mL}$ & $401.1 \pm 92.8$ & $429.4 \pm 135.1$ & $156.3 \pm 8.5$ \\
\hline & $5.0 \mathrm{mg} / 3.5 \mathrm{~mL}$ & $519.6 \pm 152.2$ & $712 \pm 163.2 \mathbb{I}$ & $278.3 \pm 30.5 \mathrm{I}$ \\
\hline \multirow[t]{5}{*}{ Aerogen Solo vibrating mesh } & $2.5 \mathrm{mg} / 3 \mathrm{~mL}$ & $711.3 \pm 214.8$ & $831.6 \pm 90.4$ & $216.6 \pm 62.8$ \\
\hline & $2.5 \mathrm{mg} / 4 \mathrm{~mL}$ & $736 \pm 246.5$ & $740.8 \pm 251.7$ & $208.3 \pm 70.9$ \\
\hline & $7.5 \mathrm{mg} / 4 \mathrm{~mL} \ddagger$ & $2,090 \pm 317.6$ & $1,872.6 \pm 533.8$ & $1,046 \pm 247.8$ \\
\hline & $2.5 \mathrm{mg} / 3.5 \mathrm{~mL}$ & $834.5 \pm 239.4$ & $897.4 \pm 252.3$ & $208.3 \pm 44.4$ \\
\hline & $5.0 \mathrm{mg} / 3.5 \mathrm{~mL} \S$ & $1,618.4 \pm 320.3$ & $1,528.2 \pm 277.6$ & $417.2 \pm 60$ \\
\hline
\end{tabular}

* Values are mean \pm SD lung dose.

$\dagger$ Drug output for $2.5 \mathrm{mg} / 4 \mathrm{~mL}$ was higher than for $2.5 \mathrm{mg} / 3 \mathrm{~mL}$ at this position.

\$ Drug output for $7.5 \mathrm{mg} / 4 \mathrm{~mL}$ was higher than for $2.5 \mathrm{mg} / 4 \mathrm{~mL}$ at all positions.

$\S$ Drug output for $5.0 \mathrm{mg} / 3.5 \mathrm{~mL}$ was higher than for $2.5 \mathrm{mg} / 3.5 \mathrm{~mL}$ at all positions.

| Drug output for $5.0 \mathrm{mg} / 3.5 \mathrm{~mL}$ was higher than for $2.5 \mathrm{mg} / 3.5 \mathrm{~mL}$ at this position.

II Drug output for $5.0 \mathrm{mg} / 3.5 \mathrm{~mL}$ was higher than for $2.5 \mathrm{mg} / 3.5 \mathrm{~mL}$ at this position.

nebulizers. Increasing the loading volume without increasing the amount of drug does not increase lung dose when using vibrating mesh nebulizers.

The problem of the effect of position has been previously looked at using adult type ventilator models.9-12 In this study we provide lung dose data achieved by different aerosol generators located on 4 different places in a pediatric ventilator model.

We found that both jet nebulizers performed better when placed at the ventilator or the humidifier. These data are in agreement with others. ${ }^{9-11}$ Hughes et al and Quinn also found that lung dose increased when the generating device was placed closer to the ventilator $\left(\mathrm{V}_{\mathrm{T}}\right.$ of $700 \mathrm{~mL}$ and $400 \mathrm{~mL}$, respectively). ${ }^{9,10}$ More recently, Ari et al compared lung dose of 3 different nebulizers (jet, ultrasonic, and vibrating mesh) placed in 3 positions (between the ETT and Y-piece, $15 \mathrm{~cm}$ from the Y-piece, and $15 \mathrm{~cm}$ from the ventilator). ${ }^{11}$ They used an adult model of mechanical ventilation, without bias flow, and with/without humidification $\left(\mathrm{V}_{\mathrm{T}} 500 \mathrm{~mL}\right.$, breathing frequency 15 breaths/min, ETT $8 \mathrm{~mm}$ ). They also found that lung dose was greater when jet nebulizers were placed at the ventilator. However, our current data are conflicting with other pediatric data using lower $\mathrm{V}_{\mathrm{T}} \cdot{ }^{6,12} \mathrm{In}$ a previous study, using a ventilator model similar to the one used in the present study, we compared lung dose achieved by a jet nebulizer (Salter 8900) and an intrapulmonary percussive ventilator device placed after the humidifier or before the Y-piece. ${ }^{6} \mathrm{We}$ found no difference in lung dose for the jet nebulizer when placed before the Y-piece or at the humidifier. In a follow-up study, Ari et al compared lung dose of a jet nebulizer placed before $15 \mathrm{~cm}$ before the $\mathrm{Y}$-piece and $15 \mathrm{~cm}$ before the humidifier with a vibrating mesh nebulizer placed at the ETT and right before the humidifier. ${ }^{12}$ They used humidified pediatric $\left(\mathrm{V}_{\mathrm{T}} 100 \mathrm{~mL}\right.$, breathing frequency 20 breaths/min, ETT $5 \mathrm{~mm}$ ) and adult $\left(\mathrm{V}_{\mathrm{T}} 500 \mathrm{~mL}\right.$, breathing frequency 20 breaths/min, ETT $8 \mathrm{~mm}$ ) ventilator models, with bias flow of either 2 or $5 \mathrm{~L} / \mathrm{min}$. They found no difference in lung dose for different positions for the jet nebulizer. One difference between their study and ours is that the jet nebulizers were operated at $2.5 \mathrm{~L} / \mathrm{min}$ and $6 \mathrm{~L} / \mathrm{min}$ in their study and our study, respectively. We speculate that the differences in lung dose seen between adult and pediatric models and 
between pediatric models of different $\mathrm{V}_{\mathrm{T}}$ might be because a certain $\mathrm{V}_{\mathrm{T}}$ is required for the differences in filter deposition to occur.

The ultrasonic nebulizer performed best when placed at the humidifier. These data are conflicting with previously published data using an adult ventilator model. ${ }^{12,15,16}$ Thomas et al, ${ }^{15}$ using an adult model (ETT $9 \mathrm{~mm}$, breathing frequency 15 breaths/min, inspiratory/expiratory ratio of 1:3, $\mathrm{V}_{\mathrm{T}} 900 \mathrm{~mL}$ ), placed the devices in the inspiratory limb at $50 \mathrm{~cm}$ and right before the Y-piece, and found no differences in lung dose. ${ }^{16}$ Ari et al, using an adult ventilator model, with no bias flow, found that placing the device $15 \mathrm{~cm}$ before the Y-piece provided the highest lung dose. The differences between their studies and ours could be due to several factors such as different ETT sizes, different ventilator settings, different devices, presence or absence of bias flow, and different placement of the devices.

The vibrating mesh nebulizer performed best when placed at either the humidifier or at the ventilator. Our results confirm those of Ari et al using a pediatric model. ${ }^{12}$ However, our delivery efficiency was 2-fold higher than the one reported by Ari et al. This difference could be due to a variety of factors such as the fact that we used a larger ventilator circuit ( $22 \mathrm{~mm}$ vs $15 \mathrm{~mm}$ inner diameter), a slightly larger ETT (5.5 mm vs $5.0 \mathrm{~mm}$ inner diameter), and a larger $\mathrm{V}_{\mathrm{T}}(200 \mathrm{~mL}$ vs $100 \mathrm{~mL})$. In addition, the nebulizer was positioned in a slightly different way in our study: the nebulizer was connected immediately after the ventilator, while in their study a corrugated tube was interposed between the ventilator and the nebulizer that was connected to the humidifier. We also provide novel data on the placement of a vibrating mesh nebulizer in a pediatric ventilator model. However, these data are in conflict with the data Ari et al obtained using an adult model that showed lung dose was greater when the device was placed either before or at the Y-piece. ${ }^{11}$ The differences are most likely due to the lack of bias flow in their study, since the same group showed a 2-fold increase in lung dose when moving the device from right before the Y-piece to before the humidifier when using a circuit with bias flow. ${ }^{12}$

We found that in a pediatric ventilator model the 2 jet nebulizers tested and the vibrating mesh nebulizer delivered more albuterol to the end of the ETT when placed at either the ventilator or the humidifier. The ultrasonic nebulizer performed best at the humidifier. The worst performance was achieved by placing the nebulizer at the $\mathrm{Y}$ piece. The position $30 \mathrm{~cm}$ before the Y-piece rendered similar results. These data confirm previous work showing that nebulizers are more efficient when placed farther away from the ETT. ${ }^{9,10,12}$ We speculate that the ventilator circuit acts as a reservoir. In addition, the speed of the aerosol that reaches the Y-piece will decrease when the aerosol gen- erator is placed away from the patient, therefore decreasing impaction of emitted aerosol.

The influence of the type of device on lung dose in ventilator models and humans has also been previously studied. ${ }^{6-8,11,12,16-18}$ However, there is paucity of data on the newly available technologies. In our study the vibrating mesh nebulizer outperformed 2 jet nebulizers in each position tested, and the ultrasonic nebulizer either at the ventilator or at the humidifier. O'Doherty et al found no difference among a jet and 2 ultrasonic nebulizers when placed before the Y-piece and using a $3 \mathrm{~mL}$ nebulizer load. ${ }^{8}$ Conversely, Harvey et al, in an in vivo study, demonstrated a 2-fold higher lung deposition with an ultrasonic nebulizer, compared to a jet nebulizer, placed before the Y-piece in an adult ventilator. ${ }^{16}$ Similar results were obtained in our study. In a previous study we found that a jet nebulizer outperformed the intrapulmonary percussive ventilator when placed at humidifier. ${ }^{6}$ Fok et al, in 2 in vivo studies (animal and neonatal), demonstrated a several-fold higher pulmonary deposition of ultrasonic nebulizers, compared to a jet nebulizer. ${ }^{17,18}$ Our data are in agreement with their findings. Our data are also in partial agreement with results from Ari et al, who found in an adult mechanical ventilation model that the vibrating mesh outperformed the jet nebulizer but not the ultrasonic nebulizer when the devices were placed either at the Y-piece or $15 \mathrm{~cm}$ before the Y-piece. ${ }^{11}$ They found no difference between devices when they were placed before the humidifier. In contrast, we found that the vibrating mesh nebulizer outperformed all other devices. These differences are most likely due to the fact that our circuit had a $2 \mathrm{~L} / \mathrm{min}$ bias flow and theirs had none. The same group reported on a pediatric and an adult ventilator model that the vibrating mesh nebulizer had a 2-fold lung dose difference, when compared to the jet nebulizer. ${ }^{12}$ Our data confirm their findings regarding the performance of vibrating mesh nebulizers. We speculate that the vibrating mesh device achieved a higher lung dose because of its design and operational characteristics. More specifically, it has a minimal dead space and it does not add extra flow to the ventilator circuit. Other authors have previously found that higher bias flow and higher nebulizer flow rates lead to lower lung doses. ${ }^{12,19}$

We found that in a pediatric ventilator model the vibrating mesh nebulizer was superior to both the jet nebulizers at all tested positions, and to the ultrasonic nebulizer when placed at either the ventilator or the humidifier.

When evaluating the effect of nebulizer loading volume/nominal dose on lung dose, we found that the increase in lung dose is not due only to an increase in loading volume, but also due to an increase in the nominal dose. This was reflected in the comparison between solutions of equal volume but different amount of albuterol $(2.5 \mathrm{mg} / 3.5 \mathrm{~mL}$ vs $5.0 \mathrm{mg} / 3.5 \mathrm{~mL}$, and $2.5 \mathrm{mg} / 4 \mathrm{~mL}$ vs $7.5 \mathrm{mg} / 4 \mathrm{~mL}$ ). We also found that increasing the loading 
volume increased lung dose for the jet and ultrasonic nebulizers but not for the vibrating mesh nebulizer. This was reflected in the comparison between 2 solutions with equal amounts of albuterol but different loading volumes. We speculate that these differences are due to the design characteristics of different nebulizer types, especially the amount of dead volume. These data are in agreement with previously published data on jet nebulizers not tested on a ventilator circuit. ${ }^{13}$ These data are also in agreement with O'Doherty et al, who found a significant increase in lung dose when increasing the loading volume of jet and ultrasonic nebulizers from $3 \mathrm{~mL}$ to $6 \mathrm{~mL}$ in an adult ventilator model. ${ }^{8}$ This study also demonstrated that increasing the nominal dose will not necessarily increase the lung dose. The vibrating mesh nebulizer showed an increase in lung dose irrespective of the position in the circuit. However, both jet nebulizers and the ultrasonic nebulizer failed to increase lung dose when placed at the Y-piece. This was also true for both jet nebulizers when positioned $30 \mathrm{~cm}$ from the Y-piece.

We found that in a pediatric ventilator model the increase in loading volume without increasing the nominal dose increases lung dose in jet and ultrasonic nebulizers, but not in vibrating mesh ones.

Our study has 2 limitations that are inherent to the in vitro nature of the study and the ventilator setup. The drug captured at the filter (lung dose) overestimates the amount of drug reaching the patient, because part of the exhaled aerosol is retained on it. This is critical for submicronic aerosols. However, this is a well established methodology that has been validated against human studies. Another limitation is that this study did not address the aerodynamic characteristics of the aerosols reaching the tip of the ETT. However, the mass median aerodynamic diameter of the aerosols generated by the nebulizers alone ranged from $3.1 \mu \mathrm{m}$ to $4.4 \mu \mathrm{m}$ (data from our laboratory and manufacturer's information). In addition, Watterberg et al, in an in vitro study, found that, although a jet nebulizer and a submicronic ultrasonic nebulizer differed in particle size when measured at the nebulizer, those differences disappeared when measured at the tip of a 4.0 mm ETT. ${ }^{20}$

Healthcare team members are now provided with delivery efficiency, lung dose, and cost data that should be used in conjunction with devices and patient characteristics, along with type of drug chosen for nebulization to personalize the care for a given patient.

\section{Conclusions}

This study provides a comparison of lung dose achieved by 4 devices placed in 4 different positions in the ventilator circuit, using different nominal doses of albuterol solution. In an in vitro pediatric ventilator model, a vibrating mesh nebulizer outperformed jet and an ultrasonic nebulizer, irrespective of their position in the ventilator cir- cuit. The nebulizers were more efficient when placed at either the ventilator or the humidifier, and less efficient when placed at either the Y-piece or $30 \mathrm{~cm}$ from the $\mathrm{Y}$ piece. The conclusions of this study are valid for the specific tested conditions. Conclusions regarding optimization of operating conditions should not be extrapolated among nebulizers of different operating principles. One important corollary of this work is that aerosol generators are part of a complex delivery device that also includes position of the device in the ventilator circuit, humidification, and type of ventilator circuit and ETT.

\section{REFERENCES}

1. Everard ML. Ethical aspects of using radiolabelling in aerosol research. Arch Dis Child 2003;88(8):659-661.

2. Fink JB, Dhand R, Grychowski J, Fahey PJ, Tobin MJ. Reconciling in vitro and in vivo measurements of aerosol delivery from a metered-dose inhaler during mechanical ventilation and defining efficiency-enhancing factors. Am J Respir Crit Care Med 1999;159(1): 63-68.

3. Miller DD, Amin MM, Palmer LB, Shah AR, Smaldone GC. Aerosol delivery and modern mechanical ventilation: in vitro/in vivo evaluation. Am J Respir Crit Care Med 2003;168(10):1205-1209.

4. Dhand R. Aerosol delivery during mechanical ventilation: from basic techniques to new devices. J Aerosol Med Pulm Drug Deliv 2008; 21(1):45-60.

5. Fink JB. Aerosol delivery to ventilated infant and pediatric patients. Respir Care 2004;49(6):653-665.

6. Berlinski A, Willis JR. Albuterol delivery by intrapulmonary percussive ventilator and jet nebulizer in a pediatric ventilator model. Respir Care 2010;55(12):1699-1704.

7. O'Riordan TG, Greco MJ, Perry RJ, Smaldone GC. Nebulizer function during mechanical ventilation. Am Rev Respir Dis 1992;145(5): 1117-1122.

8. O'Doherty MJ, Thomas SH, Page CJ, Treacher DF, Nunan TO. Delivery of a nebulized aerosol to a lung model during mechanical ventilation. Effect of ventilator settings and nebulizer type, position, and volume of fill. Am Rev Respir Dis 1992;146(2):383-388.

9. Hughes JM, Saez J. Effects of nebulizer mode and position in a mechanical ventilator circuit on dose efficiency. Respir Care 1987; 32(11):1131-1135.

10. Quinn WW. Effect of a new nebulizer position on aerosol delivery during mechanical ventilation: a bench study. Respir Care 1992; 37(5):423-431.

11. Ari A, Areabi H, Fink JB. Evaluation of aerosol generator devices at 3 locations in humidified and non-humidified circuits during adult mechanical ventilation. Respir Care 2010;55(7):837-844.

12. Ari A, Atalay OT, Harwood R, Sheard MM, Aljamhan EA, Fink JB. Influence of nebulizer type, position, and bias flow on aerosol drug delivery in simulated pediatric and adult lung models during mechanical ventilation. Respir Care 2010;55(7):845-851.

13. Hess D, Fisher D, Williams P, Pooler S, Kacmarek RM. Medication nebulizer performance. Effects of diluent volume, nebulizer flow, and nebulizer brand. Chest 1996;110(2):498-505 .

14. Berlinski A, Waldrep JC. Four hours of continuous albuterol nebulization. Chest 1998;114(3):847-853.

15. Thomas SHL, O'Doherty MJ, Page CJ, Treacher DF, and Nunan T. Delivery of ultrasonic nebulized aerosols to a lung model during mechanical ventilation. Am Rev Respir Dis 1993;148:872-878.

16. Harvey CJ, O'Doherty MJ, Page CJ, Thomas SHL, Nunan TO, Treacher DF. Comparison of jet and ultrasonic nebulizer pulmonary 


\section{Albuterol Delivery by 4 Different Nebulizers}

aerosol deposition during mechanical ventilation. Eur Respir J 1997; 10(4):905-909.

17. Fok TF, Al-Essa M, Monkman S, Dolovich M, Girard L, Coates G, Kirpalani H. Pulmonary deposition of salbutamol aerosol delivered by metered dose inhaler, jet nebulizer, and ultrasonic nebulizer in mechanically ventilated rabbits. Pediatr Res 1997;42(5):721-727.

18. Fok TF, Lam K, Ng PC, Leung TF, So HK, Cheung KL, Wong W. Delivery of salbutamol to nonventilated preterm infants by metered- dose inhaler, jet nebulizer, and ultrasonic nebulizer. Eur Respir J 1998;12(1):159-164.

19. Coleman DM, Kelly HW, McWilliams BC. Determinants of aerosolized albuterol delivery to mechanically ventilated infants. Chest 1996;109(6):1607-1613. Erratum in: Chest 1996;110(4):1130.

20. Watterberg KL, Clark AR, Kelly W, Murphy S. Delivery of aerosolized medication to intubated babies. Pediatr Pulmonol 1991;10(2):136-141

This article is approved for Continuing Respiratory Care Education credit. For information and to obtain your CRCE

(free to AARC members) visit 